\title{
Rapid antimicrobial susceptibility testing and $\beta$-lactam-induced cell morphology changes of Gram-negative biological threat pathogens by optical screening
}

Heather P. McLaughlin and David Sue (D)

\begin{abstract}
Background: For Yersinia pestis, Burkholderia pseudomallei, and Burkholderia mallei, conventional broth microdilution (BMD) is considered the gold standard for antimicrobial susceptibility testing (AST) and, depending on the species, requires an incubation period of 16-20 h, or 24-48 h according to the Clinical and Laboratory Standards Institute (CLSI) guidelines. After a diagnosis of plague, melioidosis or glanders during an outbreak or after an exposure event, the timely distribution of appropriate antibiotics for treatment or post-exposure prophylaxis of affected populations could reduce mortality rates.

Results: Herein, we developed and evaluated a rapid, automated susceptibility test for these Gram-negative bacterial pathogens based on time-lapse imaging of cells incubating in BMD microtitre drug panels using an optical screening instrument (oCelloScope). In real-time, the instrument screened each inoculated well containing broth with various concentrations of antibiotics published by CLSI for primary testing: ciprofloxacin (CIP), doxycycline (DOX) and gentamicin (GEN) for Y. pestis; imipenem (IPM), ceftazidime (CAZ) and DOX for B. mallei; and IPM, DOX, CAZ, amoxicillin-clavulanic acid (AMC) and trimethoprim-sulfamethoxazole (SXT) for B. pseudomallei. Based on automated growth kinetic data, the time required to accurately determine susceptibility decreased by $\geq 70 \%$ for $Y$. pestis and $\geq 50 \%$ for $B$. mallei and $B$. pseudomallei compared to the times required for conventional BMD testing. Susceptibility to GEN, IPM and DOX could be determined in as early as three to six hours. In the presence of CAZ, susceptibility based on instrument-derived growth values could not be determined for the majority of B. pseudomallei and B. mallei strains tested. Time-lapse video imaging of these cultures revealed that the formation of filaments in the presence of this cephalosporin at inhibitory concentrations was detected as growth. Other $\beta$-lactam-induced cell morphology changes, such as the formation of spheroplasts and rapid cell lysis, were also observed and appear to be strain- and antibiotic concentration-dependent.

Conclusions: A rapid, functional AST was developed and real-time video footage captured $\beta$-lactam-induced morphologies of wild-type B. mallei and B. pseudomallei strains in broth. Optical screening reduced the time to results required for AST of three Gram-negative biothreat pathogens using clinically relevant, first-line antibiotics compared to conventional BMD.
\end{abstract}

Keywords: Antimicrobial susceptibility testing, Cell morphology, Gram-negative biothreat agents

\footnotetext{
* Correspondence: dsue@cdc.gov

Laboratory of Preparedness and Response Branch, Division of Preparedness and Emerging Infections, National Center for Emerging and Zoonotic Infectious Diseases, Centers for Disease Control and Prevention, 1600 Clifton Road NE, MS-H17-5, Atlanta, GA 30333, USA
}

(c) The Author(s). 2018 Open Access This article is distributed under the terms of the Creative Commons Attribution 4.0 International License (http://creativecommons.org/licenses/by/4.0/), which permits unrestricted use, distribution, and reproduction in any medium, provided you give appropriate credit to the original author(s) and the source, provide a link to the Creative Commons license, and indicate if changes were made. The Creative Commons Public Domain Dedication waiver (http://creativecommons.org/publicdomain/zero/1.0/) applies to the data made available in this article, unless otherwise stated. 


\section{Background}

Yersinia pestis, Burkholderia pseudomallei, and Burkholderia mallei are designated Tier 1 biological select agents by the United States Federal Select Agent Program because their deliberate use could pose a serious risk to public health and safety. These pathogens are characterized by low infectious doses, high mortality rates, and the ease of dissemination, production and transmission $[1,2]$. Both $Y$. pestis (plague) and B. mallei (glanders) were weaponized during the twentieth century [3]. Animal herds, including horses and mules, were allegedly infected with $B$. mallei in a deliberate act against Allied forces during World War I [4]. During World War II, a biological and chemical warfare research and development unit of the Japanese military was suspected of intentionally spreading plague-infected fleas and infecting horses, civilians and prisoners of war with glanders $[4,5]$. While $Y$. pestis, B. pseudomallei, and B. mallei are classified as biothreat agents, these Gramnegative pathogens have been more frequently implicated in naturally occurring outbreaks.

As a result of three major plague pandemics, including the Black Death which claimed over $60 \%$ of the European population, this disease holds a significant place in human history and has markedly influenced the development of modern civilization [6]. While pandemics have not occurred in recent times, plague is not an eradicated disease and animal hosts still exist on all continents except Australia. Outbreaks such as the 1994 epidemics in western India which led to the evacuation of over half a million residents, and the recent Madagascar outbreak of pneumonic plague, which can spread from person to person, are reminders that plague is a dangerous infectious disease [7-9]. A small number of newly diagnosed plague cases continues to occur in the western United States, but significantly more cases are reported in parts of Africa and Asia. Bubonic plague is the most common form of the disease and is often transmitted by the bite of a flea that has left its infected host. Bacteria from these cases can spread systemically, resulting in secondary septicemia and/or pneumonia [10]. Pneumonic plague can lead to septicemic plague; both types are nearly always fatal without the administration of appropriate antibiotic therapy and care within $24 \mathrm{~h}$ of symptom onset $[10,11]$. While $Y$. pestis isolates are not intrinsically drug resistant, Russian scientists reported on quinolone-resistant strains [12] and concerns of engineered multi-drug resistant strains have been raised $[13,14]$. Furthermore, despite the rarity of drug resistant isolates, both streptomycin- and multidrug-resistant (MDR) clinical isolates have been reported [15-17].

Unlike plague, melioidosis cases are more endemic to Southeast Asia and Australia. Although glanders cases are rare and extremely sporadic, recent naturally occurring equine cases have been documented in Brazil, Pakistan and India [18-20]. Few cases of glanders and melioidosis are reported in the U.S. and with the wide-spectrum clinical manifestations, timely diagnosis and treatment could be challenging $[1,21]$. Cases of melioidosis received increased attention after the Vietnam War. Soldiers and pilots experienced variable incubation periods subsequent to pathogen exposure by aerosolization of contaminated soil and water by helicopters [22, 23].

B. pseudomallei has a highly variable and evolving genome and has been shown to possess an impressive, inherent array of resistance mechanisms, thus limiting the available antimicrobial agents for therapy [24-26]. Resistance to clinically significant antibiotics has been reported for ceftazidime (CAZ), amoxicillin-clavulanic acid (AMC), trimethoprim-sulfamethoxazole (SXT) and imipenem (IPM) [24, 27, 28]. Moreover, CAZ-resistant variants were reported in vivo in melioidosis patients undergoing CAZ therapy [29, 30]. Without prompt and appropriate antibiotic treatment, mortality rates associated with melioidosis can exceed $40 \%$ [26, 31]. B. mallei shares morphological and antigenic characteristics with $B$. pseudomallei. Besides aminoglycoside- and macrolide-susceptibility, the reported resistance profiles of B. pseudomal$l e i$ and $B$. mallei strains are similar [32-34]. The mortality rate for pulmonary glanders without treatment has been reported to be $90-95 \%$ and as the majority of human cases occurred before antibiotic treatment was available, most infected people perished [35]. Antibiotic therapy for $B$. mallei infections are similar to $B$. pseudomallei and successful treatment has been demonstrated in the few human glanders cases reported since the 1940s [32, 36, 37].

Broth microdilution (BMD) is considered the gold standard method for antimicrobial susceptibly testing (AST) based on the Clinical and Laboratory Standards Institute (CLSI) guidelines, and requires a 16 to $20 \mathrm{~h}$ incubation period for B. pseudomallei and B. mallei, and 24 to $48 \mathrm{~h}$ for $Y$. pestis [38]. Gene detection-based methods for AST can reduce the time to results, but the presence of a resistant determinant or gene mutation does not always correspond to phenotypic resistance. Genomic-based analyses rely on prior knowledge of gene(s) or mutation(s) that are responsible for a resistant phenotype and could overlook undescribed, novel resistance. To ensure appropriate antimicrobial agents are deployed in response to an outbreak or other public health emergency event, functional phenotypic susceptibility testing of biothreat agents is essential. Rapid laboratory methods including flow cytometry, bacteriophage amplification and MALDI-TOF mass spectrometry, and bioluminescent reporter phage have been described [39-41]. While these phenotypic methods are less time-consuming compared to the conventional BMD, they can be cost-prohibitive, laborintensive, and require specialized reagents and training. Rapid characterization of strain(s) implicated in an exposure or release event can also contribute to the public health 
response. General morphological changes have been described for certain bacterial species in response to $\beta$-lactam antibiotics. Some are dependent on drug concentration, binding site specificities, and the number of penicillin-binding protein targets [42, 43].

Previously we developed a simple, rapid, automated antimicrobial susceptibility test for $B$. anthracis using the optical screening instrument the oCelloScope. Timelapse video imaging of broth culture growth revealed unique chain morphology differences among $B$. anthracis strains [44]. Expanding on this work, herein we evaluated this optical screening method for Y. pestis, B. pseudomallei, and B. mallei. Real-time video imaging of bacterialantibiotic combinations in broth culture has revealed $\beta$-lactam-induced cell morphology changes of wild-type B. pseudomallei and B. mallei.

\section{Materials and methods}

\section{Bacterial strains}

Study strains of $Y$. pestis, B. pseudomallei and B. mallei are listed with antimicrobial susceptibility profiles and epidemiological data in Table 1 . The non-susceptible (NS), virulence-attenuated $Y$. pestis and B. pseudomallei strains are excluded from the HHS and USDA Federal
Select Agents and Toxins list and were developed as laboratory control strains with the consent and oversight of the CDC Institutional Biosafety Committee. Bacterial strains were stored as glycerol stocks at $-70^{\circ} \mathrm{C}$ and then cultured overnight on BD BBL ${ }^{\mathrm{Tm}}$ Trypticase Soy Agar II with 5\% sheep blood plates (SBA) (Fisher Scientific, PA) at $35^{\circ} \mathrm{C}$ in ambient air for testing. For B. pseudomallei strains Bp82 and JB039, all growth medium was supplemented with $5 \mu \mathrm{g} / \mathrm{ml}$ adenine [45].

\section{Antimicrobials}

Antimicrobial agents selected for this study were: gentamicin (GEN), ciprofloxacin (CIP) and doxycycline (DOX) for $Y$. pestis; imipenem (IPM), DOX and ceftazidime (CAZ) for B. mallei; and IPM, CAZ, DOX, amoxicillin-clavulanic acid (AMC) and trimethoprim-sulfamethoxazole (SXT) for $B$. pseudomallei. For conventional broth microdilution (BMD) testing, antimicrobial susceptibility panels were prepared in-house with Cation-Adjusted Mueller Hinton broth (CAMHB) as published by CLSI. Y. pestis strains were classified as either susceptible or resistant to GEN and DOX, or non-susceptible to CIP based on CLSI designations and conventional BMD results. B. pseudomallei strains were classified as susceptible or resistant to

Table 1 Bacterial strains used in this study and their antimicrobial susceptibility profiles

\begin{tabular}{|c|c|c|c|c|c|c|c|c|c|c|}
\hline \multirow[b]{2}{*}{ B. pseudomallei } & \multirow[b]{2}{*}{ Description } & \multirow[b]{2}{*}{ Origin } & \multirow[b]{2}{*}{ Country } & \multirow[b]{2}{*}{ Year } & \multirow[b]{2}{*}{ Ref } & \multicolumn{3}{|c|}{ Minimal Inhibitory Concentration } & \multirow{2}{*}{ SXT } & \multirow[b]{2}{*}{ DOX } \\
\hline & & & & & & AMC & CAZ & IPM & & \\
\hline Bp82 & attenuated & Laboratory & USA & 2010 & {$[45]$} & $\leq 4 / 2(S)$ & $\leq 4(S)$ & $\leq 2(\mathrm{~S})$ & $\leq 0.5 / 9.5(S)$ & $\leq 1(\mathrm{~S})$ \\
\hline JB039 & $\begin{array}{l}\text { attenuated; } \\
\text { derivative of Bp82 }\end{array}$ & Laboratory & USA & 2016 & {$[49]$} & $32 / 16(R)$ & $>128(\mathrm{R})$ & $64(\mathrm{R})$ & $>32 / 608(R)$ & $32(R)$ \\
\hline ATCC 23343 & wild-type & Human & $\mathrm{n} / \mathrm{a}$ & $<1957$ & {$[72]$} & $2 / 1(S)$ & $1(S)$ & $0.25(S)$ & $0.5 / 9.5(S)$ & $0.5(S)$ \\
\hline PHLS 14 & wild-type & Monkey & Philippines & 1990 & {$[73,74]$} & $4 / 2(S)$ & $2(S)$ & $0.25(S)$ & $2 / 38(S)$ & $1(\mathrm{~S})$ \\
\hline B7210 & wild-type & Human & Australia & 1970 & {$[74,75]$} & $4 / 2(S)$ & $2(S)$ & $0.5(S)$ & $1(S)$ & $2(S)$ \\
\hline Bp1651 & wild-type & Human & USA & $\mathrm{n} / \mathrm{a}$ & {$[76]$} & $64 / 32(R)$ & $>128(\mathrm{R})$ & $32(R)$ & $>32 / 608(\mathrm{R})$ & $16(\mathrm{R})$ \\
\hline B. mallei & Description & Origin & Country & Year & Ref & CAZ & IPM & DOX & & \\
\hline ATCC 23344 & wild-type & Human & China & 1942 & {$[72,74]$} & $1(S)$ & $\leq 1(\mathrm{~S})$ & $\leq 0.25(\mathrm{~S})$ & & \\
\hline NCTC 10260 & wild-type & Human & Turkey & 1949 & {$[72,74]$} & $4(S)$ & $\leq 1(\mathrm{~S})$ & $\leq 0.25(\mathrm{~S})$ & & \\
\hline Turkey 5 & wild-type & Human & Turkey & $\mathrm{n} / \mathrm{a}$ & {$[74,77]$} & $4(S)$ & $\leq 1(\mathrm{~S})$ & $\leq 0.25(\mathrm{~S})$ & & \\
\hline KC 1092 & wild-type & Mule & Iran & 1952 & {$[53,74,78]$} & $4(S)$ & $\leq 1(\mathrm{~S})$ & $\leq 0.25(\mathrm{~S})$ & & \\
\hline$Y$. pestis & Description & Origin & Country & Year & Ref & GEN & DOX & CIP & & \\
\hline A1122 & attenuated & Laboratory & USA & 1943 & {$[79]$} & $0.5(\mathrm{~S})$ & $2(S)$ & $0.03(\mathrm{~S})$ & & \\
\hline DSJB001 & $\begin{array}{l}\text { attenuated; } \\
\text { derivative of A1122 }\end{array}$ & Laboratory & USA & 2016 & [49] & $32(R)$ & $>32(\mathrm{R})$ & 4 (NS) & & \\
\hline Antiqua & wild-type; biovar Antiqua & Human & Congo & 1965 & {$[80,81]$} & $0.25(S)$ & $0.5(S)$ & $0.03(\mathrm{~S})$ & & \\
\hline Java 9 & wild-type; biovar Orientalis & Rat & Indonesia & 1957 & {$[80,82]$} & $0.5(S)$ & $1(S)$ & $0.06(S)$ & & \\
\hline Nicholisk 41 & wild-type; biovar Medievalis & Unknown & China & 1940 & {$[80]$} & $0.06(S)$ & $0.25(S)$ & $\leq 0.03(\mathrm{~S})$ & & \\
\hline Angola & wild-type; pestoides group & Unknown & Angola & $<1984$ & {$[80,83]$} & $0.5(S)$ & $0.25(S)$ & $0.015(S)$ & & \\
\hline
\end{tabular}

Antimicrobial susceptibility profiles were determined by conventional BMD testing based on CLSI guidelines and minimal inhibitory concentrations (MICs) were recorded in the unit of $\mu \mathrm{g} / \mathrm{ml}$. Susceptible (S), non-susceptible (NS), resistant (R) 
AMC, CAZ, IPM, SXT, and DOX. These classifications can be found in Table 1. For antimicrobial susceptibility testing using the oCelloScope instrument, custom-made Sensititre drug panels (Trek Diagnostics, ThermoFisher Scientific, NY) with wells containing desiccated antibiotics were used. For all antimicrobial agents evaluated during oCelloScope-based antimicrobial testing, the lowest concentration tested corresponds to the CLSI breakpoint for susceptibility, followed by two successive two-foldincreasing concentrations. For $Y$. pestis, the antibiotic concentrations tested were $0.25 \mu \mathrm{g} / \mathrm{ml}, 0.5 \mu \mathrm{g} / \mathrm{ml}$ and $1 \mu \mathrm{g} / \mathrm{ml} \mathrm{CIP,} 4 \mu \mathrm{g} / \mathrm{ml}, 8 \mu \mathrm{g} / \mathrm{ml}$ and $16 \mu \mathrm{g} / \mathrm{ml}$ DOX, and $4 \mu \mathrm{g} / \mathrm{ml}, 8 \mu \mathrm{g} / \mathrm{ml}$ and $16 \mu \mathrm{g} / \mathrm{ml} \mathrm{GEN}$. For B. mallei and

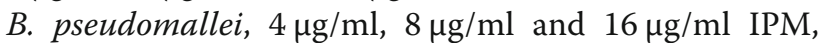

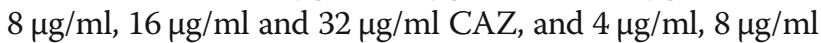
and $16 \mu \mathrm{g} / \mathrm{ml}$ DOX were tested. For B. pseudomallei, concentrations of $8 / 4 \mu \mathrm{g} / \mathrm{ml}, 16 / 8 \mu \mathrm{g} / \mathrm{ml}$ and $32 / 16 \mu \mathrm{g} / \mathrm{ml}$ AMC and $2 / 38 \mu \mathrm{g} / \mathrm{ml}, 4 / 76 \mu \mathrm{g} / \mathrm{ml}$ and $8 / 152 \mu \mathrm{g} / \mathrm{ml}$ SXT were also tested.

\section{Biosafety procedures}

Laboratory work with the attenuated, select agent-excluded strains was performed by trained personnel wearing personal protective equipment (PPE) in a BSL-2 laboratory. All experiments with wild-type strains were performed in a Class II Type A2 biological safety cabinet (BSC) located in a BSL-3 laboratory registered with the U.S. Federal Select Agent Program by trained personnel wearing PPE including a power air-purifying respirator (PAPR) and protective laboratory clothing [46].

\section{Imaging of bacterial growth in broth culture by optical screening}

Optical screening z-stack images and videos were captured using the oCelloScope instrument (BioSense Solutions ApS, Farum, Denmark) as previously described by Fredborg et al. [47] and McLaughlin et al. [44].

\section{Susceptibility testing by conventional BMD}

Antimicrobial susceptibility profiles and minimal inhibitory concentrations (MIC) outlined in Table 1 were determined by conventional broth microdilution (BMD) following CLSI guidelines [38]. Testing conditions including inoculum, medium and incubation temperature were performed according to these guidelines.

\section{Susceptibility testing by optical screening}

Each bacterial strain was inoculated into Sensititre drug panels by preparing a cell suspension per manufacturer's recommendations in Cation-Adjusted Mueller Hinton broth (CAMHB) with $\mathrm{N}$-tris(hydroxymethyl) methyl-2-aminoethanesulfonic acid (TES) (CAMHBT; Remel Inc., Lenexa, KS). First, colonies from an overnight SBA culture plate were used to prepare a cell suspension to a turbidity equal to a $0.5 \mathrm{McFarland}$ density standard for each strain. Cell suspensions were diluted in CAMHBT at 1:200 for $Y$. pestis strains and at 1:50 for B. pseudomalle $i$ and $B$. mallei strains. Drug panel wells were inoculated and then cell suspensions were transferred to a 96-well flat-bottom plate for incubation at $35^{\circ} \mathrm{C}$, as described previously [44]. For the growth kinetic experiments, plates were sealed with a breathable film cover (Breathe-Easy Sealing Membranes, Sigma Aldrich, St. Louis, MO) and placed in the oCelloScope instrument. Growth values were recorded every $20 \mathrm{~min}$ for 12 to $18 \mathrm{~h}$, as indicated. General guidelines for antimicrobial susceptibility testing using the oCelloScope instrument are described by Canali et al. [48]

\section{Analysis of optical screening instrument data}

Growth kinetic experiments and image processing were executed using UniExplorer software v. 5.0.3 as described previously [44]. Briefly, the Segmentation and Extraction Surface Area (SESA) normalized algorithm was used to obtain instrument derived growth values. This algorithm identifies bacteria within a scan area based on contrast against the background, and then calculates total bacterial surface area. Microsoft Excel Professional Plus 2013 was used to compile graphical figures. All experiments were performed twice, and figures with growth kinetic data show the mean of triplicate values \pm standard deviation (SD) from one representative experiment. The time required to determine susceptibility per strain was defined by statistical analysis of the growth data. A two-tailed t-test $(n=3)$ was used to calculate the statistical significance between a susceptible strain grown in the presence and absence of each antibiotic over time. The earliest times necessary to determine susceptibility are reported as the mean \pm standard deviation from duplicate biological experiments and a confidence level of $95 \%$ with a $p$-value less than 0.05. Categorical agreement between the optical screening method and conventional BMD for 60 bacterialantibiotic combinations was used to describe susceptibility results and interpretative errors. Concordance in AST was described as \% agreement and discrepancies were reported as \% error. In this study, a strain is susceptible by optical screening AST when divergence is observed between growth values in broth without drug and with a concentration of drug two-fold above the CLSI breakpoint for $18 \mathrm{~h} \mathrm{(Y.} \mathrm{pestis)} \mathrm{or} 12 \mathrm{~h} \mathrm{(B.} \mathrm{pseudomallei} \mathrm{and} \mathrm{B.} \mathrm{mal-}$ lei) kinetic experiments; a strain is resistant or non-susceptible by optical screening AST when growth values do not diverge. Drugs at concentrations two-fold above the CLSI breakpoints are $8 \mu \mathrm{g} / \mathrm{ml}$ GEN, $8 \mu \mathrm{g} / \mathrm{ml}$ DOX, and $0.5 \mu \mathrm{g} / \mathrm{ml} \mathrm{CIP} \mathrm{for} Y$. pestis, $8 \mu \mathrm{g} / \mathrm{ml} \mathrm{IPM,} \mathrm{4/}$ $76 \mu \mathrm{g} / \mathrm{ml} \mathrm{SXT}, 16 \mu \mathrm{g} / \mathrm{ml} \mathrm{CAZ,} 16 / 8 \mu \mathrm{g} / \mathrm{ml} \mathrm{AMC}$, and $8 \mu \mathrm{g} / \mathrm{ml}$ DOX for B. pseudomallei, and $8 \mu \mathrm{g} / \mathrm{ml}$ IPM, $8 \mu \mathrm{g} / \mathrm{ml} \mathrm{DOX}$, and $16 \mu \mathrm{g} / \mathrm{ml} \mathrm{CAZ} \mathrm{for} \mathrm{B.} \mathrm{mallei.} \mathrm{A} \mathrm{very}$ major error occurs when a strain is susceptible by the 
optical screening method, but resistant or non-susceptible by conventional BMD. A major error occurs when a strain is resistant or non-susceptible by the optical screening method, but susceptible by conventional BMD. The Segmentation and Extraction of Average Length (SEAL) algorithm was designed to detect filamentation of rodshaped bacteria based on segmentation extraction of the average bacterial length. SEAL was used to measure the average cell length $(\mu \mathrm{m})$ of Bp82 and JB039 in the presence and absence of CAZ.

\section{Results}

Rapid antimicrobial susceptibility testing of attenuated $Y$. pestis and $B$. pseudomallei strains by optical screening

Prior to testing wild-type isolates, we evaluated the oCelloScope optical screening instrument for rapid antimicrobial susceptibility testing of attenuated $Y$. pestis and B. pseudomallei strains. Antimicrobial agents used in this study are those described by CLSI for primary testing. $\mathrm{MIC}$ values were assessed for every strain by conventional
$\mathrm{BMD}$, and results were interpreted based on CLSI breakpoints (Table 1).

Real-time detection of bacterial growth was measured over $18 \mathrm{~h}$ for $Y$. pestis strains in the presence and absence of GEN (Fig. 1a), DOX (Fig. 1b), and CIP (Fig. 1c). In the absence of antibiotics, growth of the susceptible A1122 strain and the resistant/non-susceptible DSJB001 strain in CAMHBT were comparable over time. Growth values recorded in the presence of GEN, DOX, and CIP confirm DSJB001 was not inhibited at the drug concentrations equal to the CLSI breakpoints for susceptibility or at the next two two-fold concentrations above the breakpoints (Fig. 1). These results are consistent with the MIC values of DSJB001, $32 \mu \mathrm{g} / \mathrm{ml} \mathrm{GEN,} \mathrm{>} 32 \mu \mathrm{g} / \mathrm{ml} \mathrm{DOX,} \mathrm{and} 4 \mu \mathrm{g} / \mathrm{ml}$ CIP, in that growth was observed by optical screening in all concentrations of drug tested below the MICs. Growth kinetic experiments also demonstrated the growth inhibition of A1122 in the presence of all drug concentrations tested and growth differences between DSJB001 and A1122 in these conditions can be observed within the




first three to six hours. For susceptible $Y$. pestis strains, the time (in hours) required to determine susceptibility was calculated using a two-tailed t-test with a confidence level of 95\% (Table 2). These values represent the amount of time in which a statistically significant difference could be measured between the growth of a strain in broth with and without antibiotics. For A1122, susceptibility could be determined the quickest in the presence of GEN after $2.3 \pm$ $0.1,2.0 \pm 0.2$, and $1.3 \pm 0.7 \mathrm{~h}$ for 4,8 , and $16 \mu \mathrm{g} / \mathrm{ml} \mathrm{GEN}$, respectively. For both DOX and CIP, when taking into account SD values, susceptibility of A1122 was resolved in under six hours for all concentrations tested. This is a $75 \%$ reduction in time compared to a $24 \mathrm{~h}$ conventional BMD test and it is greater than an $87 \%$ reduction if the BMD test required $48 \mathrm{~h}$, which is often the case with $Y$. pestis.

For attenuated B. pseudomallei strains, growth kinetic experiments were performed over $12 \mathrm{~h}$ for the susceptible Bp82 and resistant JB039 strains in the presence and absence of AMC (Fig. 2a), SXT (Fig. 2b), IPM (Fig. 2c), and DOX (Fig. 2d). For JB039, growth response in the presence of each antibiotic at all concentrations tested were consistent with the MIC results obtained for this strain, including inhibition of growth at its MIC of 32/ $16 \mu \mathrm{g} / \mathrm{ml}$ AMC (Fig. 2a). Partial inhibition of growth was observed for JB039 at the elevated concentrations of $16 \mu \mathrm{g} / \mathrm{ml} \mathrm{IPM}$ and $16 \mu \mathrm{g} / \mathrm{ml}$ DOX (Fig. 2c and d). In the presence of drug, differences between growth of JB039 and inhibition of Bp82 could be observed within two to six hours depending on the antibiotic. Differences in growth between these susceptible and resistant B. pseudomallei strains was most rapidly detected in the presence of IPM (Fig. 2c) and the time required to determine susceptibly of Bp82 was between $1.6 \pm 0.4$ and $1.8 \pm 0.7 \mathrm{~h}$ (Table 3). The longest times required to determine susceptibly of Bp82 were in the presence CAZ which was approximately $6 \pm 2 \mathrm{~h}$ in the two-fold increasing concentrations from $8 \mu \mathrm{g} / \mathrm{ml}$ (CLSI breakpoint) to $32 \mu \mathrm{g} / \mathrm{ml}$. Automated growth kinetic experiments showed growth differences between Bp82 and JB039 were observed after approximately $6 \mathrm{~h}$ (Fig. 3a). Complementary imaging revealed CAZ-induced filamentation of Bp82 over the first six hours (Fig. 3c) followed by slow cell lysis. The SEAL algorithm can detect filamentation of rod-shaped bacteria and was used to measure the average cell length $(\mu \mathrm{m})$ of Bp82 and JB039 in the presence and absence of CAZ (Fig. 3b). Over time, cell length remained less than $5 \mu \mathrm{m}$ for both strains in broth without antibiotic as well as for the resistant JB039 strain in $8 \mu \mathrm{g} / \mathrm{ml}, 16 \mu \mathrm{g} /$

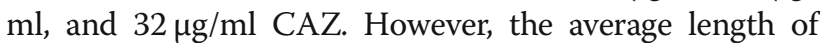
Bp82 in the presence of CAZ increased up to $55 \mu \mathrm{m}$ over the first $6 \mathrm{~h}$ during cell filamentation and subsequently decreased as cells began to lyse.

\section{Rapid antimicrobial susceptibility testing of wild-type $Y$. pestis, B. pseudomallei and B. mallei strains by optical screening}

Automated growth kinetic experiments were performed for wild-type $Y$. pestis, B. pseudomallei and B. mallei strains and times required to determine susceptibility represent the points at which a statistically significant difference was recorded between growth in the presence and absence of clinically relevant antibiotics. Four wildtype $Y$. pestis strains, representing the three biovars (Antiqua, Orientalis and Medievalis) as well as a member of the pestoides group, were tested. Depending on the antibiotic and concentration, testing by optical screening reduced the time required to determine susceptibility by 70 to $93 \%$ for all strains when compared to a 24 -h conventional BMD test. The most rapid results were obtained for GEN and DOX. The mean time requirements were

Table 2 Time (in hours) required to determine susceptibility of susceptible Y. pestis strains by optical screening and summary of categorical agreement for AST results by optical screening and conventional BMD for all strains

\begin{tabular}{|c|c|c|c|c|c|c|c|c|c|}
\hline \multirow{2}{*}{$\begin{array}{c}\text { Antimicrobial } \\
(\mu \mathrm{g} / \mathrm{ml})\end{array}$} & \multicolumn{5}{|c|}{ Y.pestis } & \multicolumn{4}{|c|}{ Summary of Categorical Agreement } \\
\hline & Angola & Nicholisk 41 & Antiqua & Java 9 & A1122 & $\begin{array}{c}\text { Optical Screening } \\
\text { Method }\end{array}$ & $\begin{array}{l}\text { Conventional } \\
\text { BMD Method }\end{array}$ & $\begin{array}{c}\% \\
\text { Agreement }\end{array}$ & $\begin{array}{c}\% \\
\text { Error }\end{array}$ \\
\hline $4 \mathrm{GEN}$ & $2.5 \pm 0.5$ & $2.4 \pm 1.3$ & $2.4 \pm 0.4$ & $1.7 \pm 0.0$ & $2.3 \pm 0.1$ & \multirow{3}{*}{$5(\mathrm{~S}), 1(\mathrm{R})$} & \multirow{3}{*}{$5(\mathrm{~S}), 1(\mathrm{R})$} & \multirow{3}{*}{$6 / 6(100 \%)$} & \multirow{3}{*}{$0 \%$} \\
\hline 8 GEN & $3.5 \pm 0.2$ & $2.8 \pm 0.8$ & $1.5 \pm 0.5$ & $2.3 \pm 0.8$ & $2.0 \pm 0.2$ & & & & \\
\hline $16 \mathrm{GEN}$ & $3.0 \pm 0.5$ & $1.2 \pm 0.7$ & $1.7 \pm 0.2$ & $1.9 \pm 0.1$ & $1.3 \pm 0.7$ & & & & \\
\hline $4 \mathrm{DOX}$ & $3.1 \pm 0.4$ & $2.2 \pm 0.5$ & $2.1 \pm 0.4$ & $2.0 \pm 0.2$ & $4.9 \pm 1.1$ & \multirow{3}{*}{$5(\mathrm{~S}), 1(\mathrm{R})$} & \multirow{3}{*}{$5(\mathrm{~S}), 1(\mathrm{R})$} & \multirow{3}{*}{$6 / 6(100 \%)$} & \multirow{3}{*}{$0 \%$} \\
\hline $8 \mathrm{DOX}$ & $2.8 \pm 0.7$ & $2.0 \pm 0.5$ & $1.9 \pm 0.1$ & $1.9 \pm 0.4$ & $3.3 \pm 0.6$ & & & & \\
\hline 16 DOX & $2.3 \pm 0.2$ & $2.3 \pm 0.4$ & $2.0 \pm 0.0$ & $2.1 \pm 0.1$ & $2.7 \pm 0.2$ & & & & \\
\hline 0.25 CIP & $5.3 \pm 1.2$ & $4.3 \pm 2.4$ & $5.3 \pm 1.7$ & $5.0 \pm 0.2$ & $3.6 \pm 2.2$ & \multirow{3}{*}{$5(\mathrm{~S}), 1(\mathrm{NS})$} & \multirow{3}{*}{$5(\mathrm{~S}), 1(\mathrm{NS})$} & \multirow{3}{*}{$6 / 6(100 \%)$} & \multirow{3}{*}{$0 \%$} \\
\hline 0.5 CIP & $4.9 \pm 1.8$ & $4.3 \pm 0.5$ & $2.0 \pm 0.7$ & $3.4 \pm 0.1$ & $2.9 \pm 1.2$ & & & & \\
\hline $1 \mathrm{CIP}$ & $4.6 \pm 2.7$ & $3.7 \pm 0.7$ & $2.8 \pm 0.9$ & $3.7 \pm 0.2$ & $2.2 \pm 0.2$ & & & & \\
\hline
\end{tabular}

For susceptible $Y$. pestis strains, the time (in hours) required to determine susceptibility by optical screening is described with a confidence level of $95 \%$ ( $p$-value $\leq 0.05$ ). The categorical agreement for susceptibility to GEN, DOX, and CIP for all strains is summarized. Concentrations in blue are equal to the CLSI breakpoint for susceptibility. Strains were grown over an $18 \mathrm{~h}$ period and time measurements represent the mean \pm standard deviation of duplicate biological experiments $(n=3)$. The number of $(S)$ susceptible, (R) resistant, and (NS) non-susceptible strains, the percentage of categorical agreement and the percentage of error (very major and major) are displayed. DSJB001 was the resistant/non-susceptible strain evaluated 


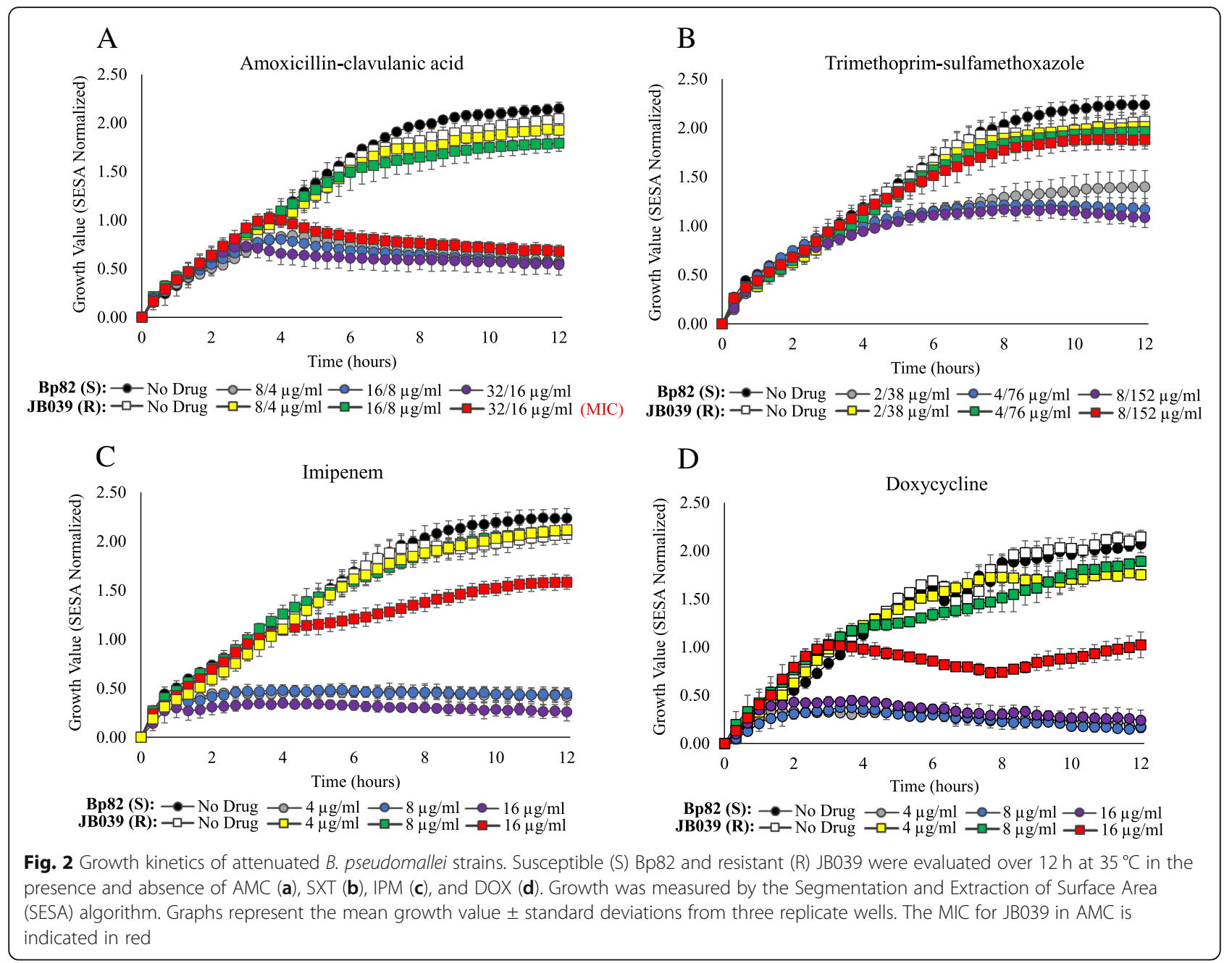

comparable between the four strains ranging from $1.7 \pm 0.0$ $\mathrm{h}$ for Java 9 in $4 \mu \mathrm{g} / \mathrm{ml}$ GEN to $3.5 \pm 0.2 \mathrm{~h}$ for Angola in $8 \mu \mathrm{g} / \mathrm{ml} \mathrm{GEN} \mathrm{(Table} \mathrm{2).} \mathrm{Determination} \mathrm{of} \mathrm{CIP} \mathrm{susceptibility}$ was slightly less rapid for all wild-type $Y$. pestis strains with the longest mean time of $5.3 \pm 1.7 \mathrm{~h}$ recorded for Antiqua. The categorical agreement observed between the optical screening method and conventional BMD was 100\% among the four wild-type strains, as well as the two attenuated control strains, in CIP, DOX, and GEN (Table 2). A representative real-time video of $Y$. pestis Angola in broth culture without the presence of antibiotics shows this coccobacilli growing in short chains over time (Additional file 1: Video 1). Similar growth patterns and cell morphologies were recorded for all $Y$. pestis strains grown in broth and no apparent antibiotic-induced cell morphology changes were observed in the presence of CIP, GEN, or DOX (data not shown).

For three wild-type B. pseudomallei strains, ATCC 23343, PHLS 14 and B7210, susceptibility could be resolved most rapidly in the presence of IPM and DOX (in under five hours for all concentrations tested) which resulted in up to a $75 \%$ reduction of time compared to a conventional 16-20 h BMD. Susceptibility to IPM and DOX could be determined in the shortest amount of time for B. pseudomallei ATCC 23343 with mean values between $1.6 \pm 0.6$ and $2.4 \pm 0.6 \mathrm{~h}$ (Table 3). For SXT testing, the time to determine susceptibility for ATCC 23343 and B7210 was rapid and comparable to those times required for IPM and DOX; however, B. pseudomallei PHLS 14 required nearly $8 \mathrm{~h}$ in SXT. Complementary video imaging showed slight elongation of PHLS 14 cells in the presence of SXT, which was not observed for ATCC 23343 or B7210 (data not shown). Susceptibility testing of four wildtype B. mallei strains in IPM and DOX yielded similar results to those obtained for $B$. pseudomallei strains (Table 3). At concentrations above the breakpoints of $4 \mu \mathrm{g} / \mathrm{ml}$ IPM and DOX, B. mallei Turkey 5 required the longest determination times of the Burkholderia spp. strains tested; between $4.6 \pm 0.8$ and $5.0 \pm 1.2 \mathrm{~h}$ for $8 \mu \mathrm{g} / \mathrm{ml}$ IPM and $16 \mu \mathrm{g} / \mathrm{ml}$ DOX, respectively. For IPM, DOX, SXT, and AMC, there was a 100\% categorical agreement between the optical screening and conventional BMD 
Table 3 Time (in hours) required to determine susceptibility of susceptible Burkholderia strains by optical screening and summary of categorical agreement for AST results by optical screening and conventional BMD results for all strains

\begin{tabular}{|c|c|c|c|c|c|c|c|c|c|}
\hline \multirow{2}{*}{$\begin{array}{c}\text { Antimicrobial } \\
(\mu \mathrm{g} / \mathrm{ml})\end{array}$} & \multicolumn{4}{|c|}{ B. mallei } & \multicolumn{5}{|c|}{ Summary of Categorical Agreement } \\
\hline & ATCC 23344 & NCTC 10260 & Turkey 5 & KC1092 & $\begin{array}{c}\text { Optical Screening } \\
\text { Method }\end{array}$ & $\begin{array}{l}\text { Conventional } \\
\text { BMD Method } \\
\end{array}$ & $\begin{array}{c}\% \\
\text { Agreement } \\
\end{array}$ & \multicolumn{2}{|c|}{\begin{tabular}{l}
\multicolumn{2}{c}{$\%$ Error } \\
Very Major $\quad$ Major \\
\end{tabular}} \\
\hline 4 IPM & $2.5 \pm 0.5$ & $3.4 \pm 0.6$ & $4.7 \pm 1.0$ & $5.2 \pm 1.2$ & & & & & \\
\hline 8 IPM & $2.9 \pm 0.4$ & $4.6 \pm 0.1$ & $4.6 \pm 0.8$ & $4.1 \pm 0.1$ & $4(\mathrm{~S}), 0(\mathrm{R})$ & $4(\mathrm{~S}), 0(\mathrm{R})$ & $4 / 4(100 \%)$ & $0 \%$ & $0 \%$ \\
\hline 16 IPM & $2.3 \pm 0.4$ & $3.5 \pm 0.0$ & $4.8 \pm 0.8$ & $3.1 \pm 0.4$ & & & & & \\
\hline $4 \mathrm{DOX}$ & $1.2 \pm 0.5$ & $2.5 \pm 0.7$ & $4.6 \pm 1.1$ & $2.2 \pm 1.4$ & & & & & \\
\hline $8 \mathrm{DOX}$ & $1.9 \pm 1.3$ & $2.9 \pm 0.4$ & $4.7 \pm 1.0$ & $3.2 \pm 1.2$ & $4(\mathrm{~S}), 0(\mathrm{R})$ & $4(\mathrm{~S}), 0(\mathrm{R})$ & $4 / 4(100 \%)$ & $0 \%$ & $0 \%$ \\
\hline $16 \mathrm{DOX}$ & $3.6 \pm 0.8$ & $3.1 \pm 1.3$ & $5.0 \pm 1.2$ & $3.8 \pm 1.8$ & & & & & \\
\hline $8 \mathrm{CAZ}$ & $11.3 \pm 0.8$ & UNDETM & $9.8 \pm 1.8$ & UNDETM & & & & & \\
\hline $16 \mathrm{CAZ}$ & UNDETM / 7.7 & UNDETM & $10.3 \pm 1.9$ & UNDETM & $1(\mathrm{~S}), 3(\mathrm{R})$ & $4(\mathrm{~S}), 0(\mathrm{R})$ & $1 / 4(25 \%)$ & $0 \%$ & $3 / 4(75 \%)$ \\
\hline $32 \mathrm{CAZ}$ & 8.7/ UNDETM & UNDETM & $10.6 \pm 1.5$ & UNDETM & & & & & \\
\hline \multirow{2}{*}{$\begin{array}{c}\text { Antimicrobial } \\
(\mu \mathrm{g} / \mathrm{ml})\end{array}$} & \multicolumn{4}{|c|}{ B. pseudomallei } & \multicolumn{5}{|c|}{ Summary of Categorical Agreement } \\
\hline & ATCC 23343 & PHLS 14 & B7210 & Bp82 & $\begin{array}{c}\text { Optical Screening } \\
\text { Method }\end{array}$ & $\begin{array}{l}\text { Conventional } \\
\text { BMD Method }\end{array}$ & $\begin{array}{c}\% \\
\text { Agreement }\end{array}$ & $\begin{array}{r}\% \text { Err } \\
\text { Very Major }\end{array}$ & Major \\
\hline 4 IPM & $2.4 \pm 0.6$ & $3.2 \pm 0.7$ & $3.1 \pm 0.6$ & $1.8 \pm 0.7$ & \multirow{3}{*}{$4(\mathrm{~S}), 2(\mathrm{R})$} & \multirow{3}{*}{$4(\mathrm{~S}), 2(\mathrm{R})$} & \multirow{3}{*}{$6 / 6(100 \%)$} & \multirow{3}{*}{$0 \%$} & \multirow{3}{*}{$0 \%$} \\
\hline 8 IPM & $1.7 \pm 0.7$ & $3.8 \pm 0.0$ & $3.8 \pm 0.5$ & $1.7 \pm 0.5$ & & & & & \\
\hline 16 IPM & $1.6 \pm 0.6$ & $3.8 \pm 0.9$ & $3.2 \pm 0.2$ & $1.6 \pm 0.4$ & & & & & \\
\hline 2/38 SXT & $2.5 \pm 1.2$ & $7.5 \pm 0.2$ & $3.5 \pm 0.9$ & $4.1 \pm 1.1$ & \multirow{3}{*}{$4(\mathrm{~S}), 2(\mathrm{R})$} & \multirow{3}{*}{$4(\mathrm{~S}), 2(\mathrm{R})$} & \multirow{3}{*}{$6 / 6(100 \%)$} & \multirow{3}{*}{$0 \%$} & \multirow{3}{*}{$0 \%$} \\
\hline 4/76 SXT & $2.3 \pm 0.2$ & $7.5 \pm 0.2$ & $3.1 \pm 1.5$ & $3.7 \pm 1.4$ & & & & & \\
\hline $8 / 152 \mathrm{SXT}$ & $1.9 \pm 0.4$ & $7.4 \pm 0.4$ & $3.2 \pm 0.5$ & $3.4 \pm 1.5$ & & & & & \\
\hline $8 \mathrm{CAZ}$ & UNDETM & UNDETM & UNDETM & $6.3 \pm 2.4$ & \multirow{3}{*}{$1(\mathrm{~S}), 5(\mathrm{R})$} & \multirow{3}{*}{$4(\mathrm{~S}), 2(\mathrm{R})$} & \multirow{3}{*}{$3 / 6(50 \%)$} & \multirow{3}{*}{$0 \%$} & \multirow{3}{*}{$3 / 6(50 \%)$} \\
\hline $16 \mathrm{CAZ}$ & UNDETM & UNDETM & UNDETM & $6.3 \pm 2.0$ & & & & & \\
\hline $32 \mathrm{CAZ}$ & UNDETM & UNDETM & UNDETM & $6.0 \pm 2.1$ & & & & & \\
\hline 8/4 AMC & $6.8 \pm 0.9$ & $7.9 \pm 0.4$ & UNDETM & $4.6 \pm 0.4$ & \multirow{3}{*}{$4(\mathrm{~S}), 2(\mathrm{R})$} & & & & \\
\hline 16/8 AMC & $4.5 \pm 0.5$ & $4.5 \pm 0.2$ & $7.3 \pm 0.6$ & $3.7 \pm 0.0$ & & $4(\mathrm{~S}), 2(\mathrm{R})$ & $6 / 6(100 \%)$ & $0 \%$ & $0 \%$ \\
\hline $32 / 16$ AMC & $3.3 \pm 0.2$ & $3.9 \pm 0.1$ & $4.0 \pm 0.5$ & $3.8 \pm 0.8$ & & & & & \\
\hline $4 \mathrm{DOX}$ & $1.6 \pm 0.8$ & $3.7 \pm 1.0$ & $3.0 \pm 0.7$ & $2.3 \pm 0.4$ & & & & & \\
\hline $8 \mathrm{DOX}$ & $2.3 \pm 0.1$ & $3.8 \pm 0.9$ & $2.9 \pm 0.1$ & $3.0 \pm 1.2$ & $4(\mathrm{~S}), 2(\mathrm{R})$ & $4(\mathrm{~S}), 2(\mathrm{R})$ & $6 / 6(100 \%)$ & $0 \%$ & $0 \%$ \\
\hline 16 DOX & $2.4 \pm 0.1$ & $3.5 \pm 0.2$ & $3.3 \pm 0.7$ & $2.9 \pm 0.8$ & & & & & \\
\hline
\end{tabular}

For susceptible Burkholderia strains, the time (in hours) required to determine susceptibility by optical screening is described with a confidence level of $95 \%$ ( $p$-value $\leq 0.05$ ). The categorical agreement for susceptibility to IPM, DOX, CAZ, SXT, and AMC is summarized. Concentrations in blue are equal to the CLSI breakpoint for susceptibility. Strains were grown over a $12 \mathrm{~h}$ period and time measurements represent the mean \pm standard deviation of duplicate biological experiments $(n=3)$. The time required to predict susceptibility to CAZ and AMC was indicated as undetermined (UNDETM) due to antimicrobial-induced filamentation. The number of (S) susceptible and (R) resistant strains, the percentage of categorical agreement and the percentage of error are displayed. Bp1651 and JB039 were the resistant strains evaluated

methods among all B. pseudomallei and B. mallei strains tested (Table 3).

\section{Ceftazidime susceptibility testing and $\beta$-lactam-induced cell morphology changes in Burkholderia pseudomallei and mallei}

Instrument-derived growth values could not be used to determine susceptibility to CAZ for the Burkholderia strains tested, except $B$. mallei Turkey 5 which required over $10 \mathrm{~h}$ (Table 3). Growth kinetic graphs and corresponding images of these susceptible cultures at $8 \mathrm{~h}$ revealed the formation of filaments in the presence of $\mathrm{CAZ}$ was detected as growth (Fig. 4). Therefore, a statistically significant difference between growth in the presence and absence of this antibiotic could not be established. For instance, growth values obtained for the CAZ-susceptible strains B. pseudomallei ATCC 23343 and B. mallei NCTC 10260 in the presence of $16 \mu \mathrm{g} / \mathrm{ml} \mathrm{CAZ} \mathrm{were} \mathrm{comparable}$ to those obtained for growth in no drug medium (Fig. 4b and $c$ ). These findings are similar to the results from the resistant B. pseudomallei 1651 strain in Fig. 4a. As a result, the categorical agreement between optical screening and BMD for CAZ was 25\% (75\% major error) and 50\% (50\% major error) for B. mallei and B. pseudomallei, respectively (Table 3 ). In contrast, statistically significant differences in later growth values were observed for $B$. mallei Turkey 5 in the presence and absence of CAZ, and for some replicates of ATCC 23344. Imaging showed an initial formation of filaments followed by slow cell lysis after prolonged drug exposure (Fig. 4d).

Based on real-time video imaging of broth cultures, Additional file 2: Table S1 summarizes $\beta$-lactam-induced cell morphology changes observed for the drug-susceptible Burkholderia strains. Real-time imaging acquired for B. pseudomallei strains ATCC 23343, PHLS 14, and B7210, and B. mallei strains NCTC 10260 and KC1092 in broth containing CAZ all depict the formation of cell filaments over a 12 $\mathrm{h}$ period (Additional file 2: Table S1). Representative videos 


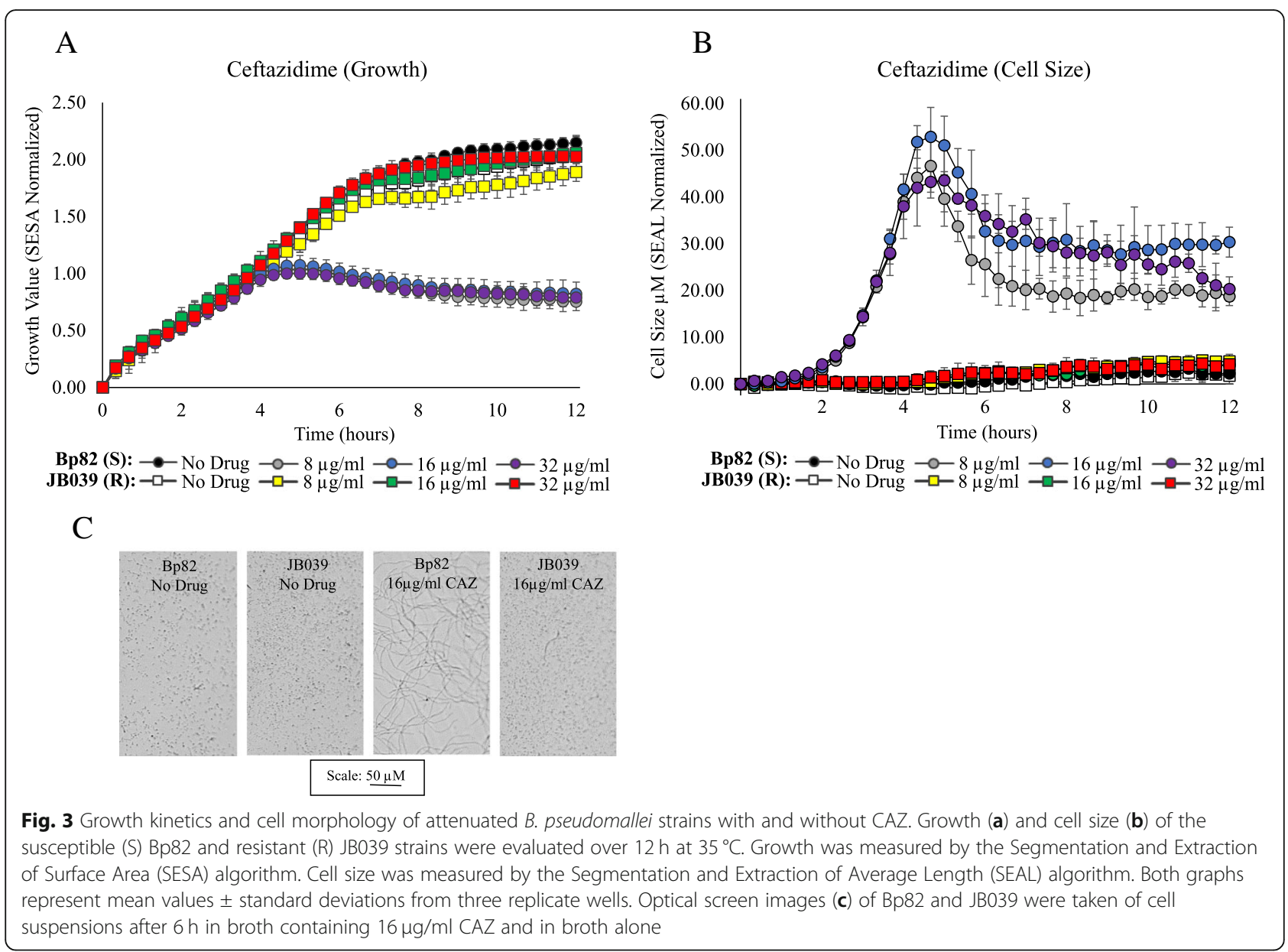

of Burkholderia strains grown in $16 \mu \mathrm{g} / \mathrm{ml} \mathrm{CAZ} \mathrm{capture}$ this cephalosporin-induced response for $B$. pseudomallei ATCC 23343 (Additional file 3: Video 2) and $B$. mallei NCTC 10260 (Additional file 4: Video 3). For comparative purposes, growth of these two type strains and the resistant B. pseudomallei 1651 strain in the absence of antibiotics can be seen in Additional file 5: Video 4, Additional file 6: Video 5 and Additional file 7: Video 6 . While strains appeared to aggregate differently during growth in broth without antibiotics, there was no evidence of cell elongation for Burkholderia strains tested in drug-free conditions. However, formation of short filaments were observed for the resistant strain B. pseudomallei 1651 in 16 and $32 \mu \mathrm{g} / \mathrm{ml} \mathrm{CAZ} \mathrm{over} \mathrm{time} \mathrm{and} \mathrm{in} \mathrm{16/}$ $8 \mu \mathrm{g} / \mathrm{ml}$ AMC during initial logarithmic phase. (Additional file 8: Video 7 and Additional file 9: Video 8 and Fig. 4e).

Observations of B. pseudomallei strains in the presence of AMC highlight both concentration- and strain-specific cell morphology changes. For example, the dominant cell morphology of B. pseudomallei ATCC 23343 after incubation in $8 / 4 \mu \mathrm{g} / \mathrm{ml} \mathrm{AMC}$, equal to the CLSI breakpoint for susceptibility, consisted of filaments. Exposure to the two-fold higher concentration of $16 / 8 \mu \mathrm{g} / \mathrm{ml} \mathrm{AMC} \mathrm{resulted}$ in the formation of more spheroplasts, and only spheroplasts could be visualized for this strain grown in the next highest concentration of $32 / 16 \mu \mathrm{g} / \mathrm{ml}$. These concentrationdependent AMC-induced morphologies of ATCC 23343 captured at $8 / 4,16 / 8$, and $32 / 16 \mu \mathrm{g} / \mathrm{ml}$ can be observed in Additional file 10: Video 9, Additional file 11: Video 10, and Additional file 12: Video 11, respectively. Due to the formation of filaments, AMC susceptibility was undetermined for one strain, B. pseudomallei B7210, in one concentration $(8 / 4 \mu \mathrm{g} / \mathrm{ml})$ (Table 3 and Additional file 2: Table S1). As growth in the presence of IPM resulted in rapid cell lysis for all B. pseudomallei and B. mallei strains tested, the time required to determine susceptibility in this drug is short. For example, video imaging of $B$. mallei $\mathrm{KC} 1092$ in $8 \mu \mathrm{g} / \mathrm{ml}$ IPM captured rapid cell lysis beginning approximately $2 \mathrm{~h}$ after drug exposure (Additional file 13: Video 12).

\section{Discussion}

Optical screening by the oCelloScope instrument reduced the time needed to accurately assess antimicrobial 


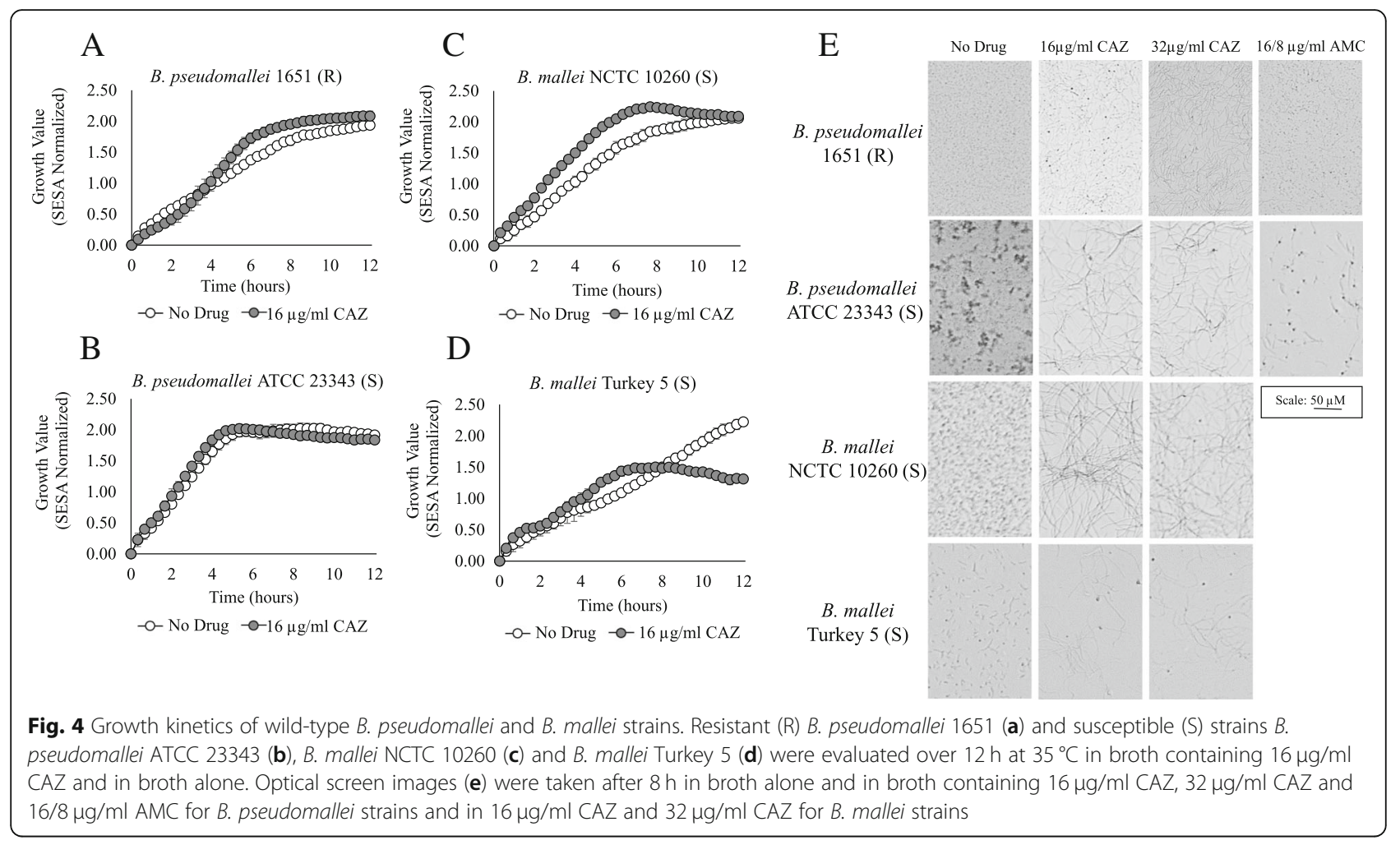

susceptibility of Gram-negative bacterial pathogens $Y$. pestis, B. pseudomallei and B. mallei. Results are measured in real-time and are available within a few hours, rather than overnight or days. Growth kinetic graphs are plotted automatically by the instrument software in real-time and the data is immediately observable by a laboratorian. Optical screening can detect biological differences in growth rate or cell morphology by comparing the wells of broth culture with and without drug for any strain tested. The predictions of susceptibility by optical screening are based on the growth observations of the same strain in these wells, and do not rely on growth of a control strain. In the presence of antibiotics, the observed growth responses for resistant and susceptible attenuated study strains were consistent with MIC values determined by conventional testing. The laboratory reagents needed for this rapid test and for a conventional BMD are the same, and all drug panels must be inoculated with a cell culture suspension. By contrast, the optical screening method replaces the subjective, visual interpretation of growth/no growth with automated instrument measurements. This method addresses the challenges associated with visually observing BMD plates for bacterial biothreat agents by a laboratory scientist, who must discern growth in small volumes of broth through a BSC wearing the PPE that is necessary for BSL-3 work. Rapid AST for $Y$. pestis by laser light scattering was described previously and requires $<6 \mathrm{~h}$, but the instrument is limited to 16 cuvettes per experiment [49].
Evaluating strain/antibiotic combinations by optical screening in a 96-well plate allows for higher throughput testing and real-time video imaging. Other rapid phenotypic AST methods for $Y$. pestis, including bioluminescent reporter phage-based or flow cytometry methods are more laborintensive and require subsequent laboratory handling or manipulation of the drug panel post inoculation $[50,51]$. After a plague infection is confirmed and the strain has been isolated, rapid and simple susceptibility profiles could be completed in a few hours of testing by optical screening. This is significant as the mortality rate associated with primary pneumonic plague is high when the appropriate antibiotics are not administered within 18$24 \mathrm{~h}$ post-symptom onset.

Treatment of melioidosis is divided into two phases that combine the urgency of treating septicemic patients and preventing death (the acute phase) with the need for eliminating persistent disease and preventing relapse (the eradication phase). Several studies reported similarities between the antimicrobial susceptibility profiles of B. mallei and B. pseudomallei and clinically relevant antibiotics for the treatment of melioidosis, such as CAZ, DOX, and IPM, were effective for the treatment of glanders [32, 33, 52, 53]. Consistent with previous reports, MICs reported here indicate similar antimicrobial activity for both species. Two rapid phenotypic antimicrobial susceptibility tests were previously described for $B$. pseudomallei using laser light scattering technology and 
bacteriophage amplification/MALDI-TOF MS [39, 49]. Both methods significantly reduced the time required for susceptibility testing compared to conventional methods, but these studies only evaluated the attenuated Bp82 strain and its resistant derivatives. As a rapid AST method for B. mallei has not yet been described in the literature, this work represents the first rapid method for wild-type strains of B. pseudomallei and B. mallei. With the exception of CAZ, the time required to accurately determine susceptibly decreased by at least half for $B$. mallei and $B$. pseudomallei compared to the times required for conventional BMD testing. The slowest susceptibility result based on the optical screening data obtained for Burkholderia strains tested in both IPM and DOX was acquired 9+ hours faster than the earliest BMD result would be available $(16 \mathrm{~h})$. The rapid results could considerably expedite administration of proper antibiotic therapy during an outbreak or after an exposure event.

Real-time video imaging captured by the oCelloScope allows visualization of bacterial growth simultaneously while performing AST. In a previous study using this optical screening technology, susceptibility of $B$. anthracis could be rapidly determined in $\leq 4 \mathrm{~h}$ and unexpected differences in growth characteristics were observed among strains in the presence and absence of penicillin [44]. Three distinct morphotypes of B. anthracis were recorded for replicating cells in broth culture in the absence of antibiotics and some strains took on a crinkled type of morphology in the presence of penicillin. Here, strains of $B$. pseudomallei also appeared to aggregate differently during growth in broth without antibiotics. This highlights the importance of evaluating an assay with a diverse set of isolates. While the $B$. mallei and $Y$. pestis strains selected for this study represent diverse origins and biovars, no differences in cell morphologies were observed among strains during growth in the absence of antibiotics.

Certain Gram-negative bacteria exhibit well-defined morphological changes in response to $\beta$-lactam antibiotics including rapid cell lysis, formation of cell wall-deficient spherical cells or filaments [42, 43]. $\beta$-lactams covalently bind to penicillin-binding proteins (PBPs) inhibiting the final stage of peptidoglycan (PG) synthesis. While several PBPs are required for PG formation, cell elongation and maintenance of the characteristic Gram-negative rod shape, inactivation of specific PBPs targeted by $\beta$-lactam drugs results in well described morphological changes [54-56]. Previous studies report that inactivation of PBP $1 \mathrm{~A}$ and $1 \mathrm{~B}$ leads to rapid cell lysis, inhibition of PBP 2 results in the formation of spheroplasts and disruption of PBP 3 causes the formation of long cell filaments [56-58]. In $Y$. pestis, filament formation resulted from furazlocillin binding to PBP 3, and amdinocillin targeting PBP 2 caused the formation of round cells [59]. No cell morphology changes were observed in our study for $Y$. pestis in the presence of CIP, DOX or GEN, but these clinically relevant antibiotics for treatment of plague are not members of the $\beta$-lactam group.

For both B. pseudomallei and B. mallei, growth differences of susceptible strains in the presence and absence of CAZ could not be determined rapidly by optical screening. In $E$. coli and P. aeruginosa, the primary activity of CAZ is against PBP 3, and antimicrobial resistance in $B$. pseudomallei involves the loss of BPSS1219, the gene encoding a PBP 3 [29, 60]. Here, we observed CAZ-induced filamentation for all Burkholderia strains tested at the drug concentrations 8,16 , and $32 \mu \mathrm{g} / \mathrm{ml}$. These concentrations are two to 32 times higher than the MIC values for these study strains. As the majority of strains remained filamentous over the entire $12 \mathrm{~h}$ of observation, determination of susceptibility was complicated by elongation of cells being interpreted as growth. Fredborg et al. [61] demonstrated early detection of $\beta$-lactam-mediated filamentation in susceptible $E$. coli strains followed by cell lysis in the latter hours using the oCelloScope; a similar phenomenon we observed for our B. pseudomallei Bp82 and $B$. mallei Turkey 5 study strains. They also show both antibiotic- and concentration-dependent variations in filamentaion. While antibiotic susceptibility is not directly correlated with filamentation, investigations using additional image analysis algorithms could discern differences in early $\beta$-lactam-induced morphology changes and could inform timely administration of appropriate antibiotics.

While there have been no other published accounts of $\beta$-lactam-induced cell morphology changes in $B$. mallei, filamentation observed for $B$. pseudomallei strains is consistent with research by Chen et al. [62]. In that study, cell elongation was evident for the susceptible B. pseudomallei strain KHW in broth containing CAZ at one quarter the MIC and at up to 16 times the MIC. Chen et al. also recommended exercising caution when reducing or discontinuing dosage upon observations of improvement by a melioidosis patient as filamentation induced by sublethal concentrations of CAZ could be reversed when antibiotics were removed, and reverting bacteria were shown to be resistant [62]. While little is known about the morphology of resistant B. pseudomallei and B. mallei strains in the presence of antibiotics, we observed slight filamentation of the multidrug resistant Bp1651 strain in the presence of CAZ over time and during the initial logarithmic growth phase in AMC. Similarly, resistant $E$. coli has also been shown to form filaments in lag and initial logarithmic phases in the presence of the $\beta$-lactam drug cefotaxime [63]. $\beta$-lactam-induced filamentation may be an intrinsic $B$. pseudomallei response regardless of whether the strain is drug resistant or susceptible, although further study is needed. 
Amoxicillin selectively binds to PBP 4 in E.coli, while clavulanate preferentially binds to PBP 2 in E. coli and to PBP 3 in Streptococcus pneumoniae [64-66]. Observations of various bacterial cell morphologies have been described in the presence of combination drugs and could be indicative of a synergistic effect of complementary binding to PBPs $[67,68]$. E. coli cells exposed to a combination of clavulanate and cephalexin exhibited reduced filamentation, emergence of spheroplasts and empty sacculi of lysed bacteria [64]. Here, we demonstrate both concentration- and straindependent cell morphologies for B. pseudomallei strains in the presence of the combination drug AMC. For all wild-type strains evaluated, filaments were the dominant cell morphology type at the breakpoint for susceptibility, but an increase in spheroplast formation was observed with increasing AMC concentrations. In Gram-negative bacteria, the primary target of IPM is PBP 2, and in the $E$. coli strain MC4100, it was reported that IPM and ceftriaxone also had a greater affinity for PBP $1 \mathrm{~b}$ compared to other drugs $[69,70]$. Inhibition of PBP 2 and PBP $1 b$ by drugs such as IPM results in the formation of spheroplasts and rapid cell lysis which is consistent with time-kill studies for B. pseudomallei that demonstrated IPM kills more rapidly compared to other drugs [71]. Likewise, we observed both rapid cell lysis via real-time video imaging and rapid determination of antimicrobial susceptibly for all Burkholderia strains evaluated.

Evaluation of these biothreat pathogens by optical screening shortened the time needed to determine antimicrobial susceptibility and revealed distinct growth characteristics in broth culture. Using this method, a limited range of relevant drug concentrations was sufficient to determine susceptibility for the study strains of $Y$. pestis, B. pseudomallei and B. mallei tested. Here, bacterial-antibiotic combinations were analyzed for categorical agreement between AST results obtained by optical screening and conventional BMD. With the exception of CAZ, the categorical agreement was $100 \%$ for all drugs tested among the study stains. The rapid AST method described here also reduces the number of steps where pathogenic cultures are handled by a laboratorian which can improve biosafety. In contrast to AST methods that rely on endpoint growth assessments, optical screening measurements are collected in real-time and can be retrieved indefinitely as primary data files. Biosecurity and containment constraints as well as the limited number of resistant strains available make it more challenging to assess rapid ASTs for bacterial biothreat agents. Future studies to evaluate additional strains would aid in assessing the performance characteristics of this method. Real-time video imaging of bacterial-antibiotic combinations has captured $\beta$-lactam-induced cell morphology changes in wild-type $B$. pseudomallei and B. mallei strains. These cell changes are consistent with the well-defined morphological observations for other Gram-negative pathogens. A better understanding of these responsive morphologies and of $\beta$-lactam PBP targets in B. pseudomallei and B. mallei could contribute to development of improved phenotypic and genotypic susceptibility testing. Observation of a well-characterized cell morphology in combination with a rapid genetic test that can confirm the absence of a specific PBP targeted by a clinically relevant antibiotic may better inform the selection of therapeutics. An understanding of cell morphology changes in B. pseudomallei and B. mallei strains could reveal characteristics that contribute to more meaningful clinical decisions or by providing critical strain-specific information for the epidemiological investigation.

\section{Conclusions}

For plague, melioidosis, and glanders, the prompt treatment of patients with the appropriate antimicrobial agents could reduce mortality rates. Optical screening can rapidly and accurately assess antimicrobial susceptibility using data collected in real-time for $Y$. pestis, B. pseudomallei and $B$. mallei. Here we demonstrate a rapid, functional AST and show real-time time video footage of $\beta$-lactam-induced morphologies of wild-type B. mallei and B. pseudomallei strains in broth. Optical screening reduced the testing time required for AST of three Gram-negative biothreat pathogens using clinically relevant, first-line antibiotics compared to conventional BMD.

\section{Additional files}

Additional file 1: Video 1. Video imaging of $Y$. pestis Angola in broth without drug. (MP4 $3041 \mathrm{~kb}$ )

Additional file 2: Table S1. $\beta$-lactam-induced cell morphology changes in susceptible Burkholderia strains. (DOCX 22 kb)

Additional file 3: Video 2. Video imaging of B. pseudomallei ATCC 23343 in broth containing 16 mg/ml CAZ. (MP4 1187 kb)

Additional file 4: Video 3. Video imaging of B. mallei NCTC 10260 in broth containing $16 \mu \mathrm{g} / \mathrm{ml}$ CAZ. (MP4 $3072 \mathrm{~kb}$ )

Additional file 5: Video 4. Video imaging of B. pseudomallei ATCC 23343 in broth without drug. (MP4 1822 kb)

Additional file 6: Video 5. Video imaging of B. mallei NCTC 10260 in broth without drug. (MP4 $3031 \mathrm{~kb}$ )

Additional file 7: Video 6. Video imaging of B. pseudomallei 1651 in broth without drug. (MP4 $1761 \mathrm{~kb}$ )

Additional file 8: Video 7. Video imaging of B. pseudomallei 1651 in broth containing $16 \mu \mathrm{g} / \mathrm{ml}$ CAZ. (MP4 $1986 \mathrm{~kb}$ )

Additional file 9: Video 8. Video imaging of B. pseudomallei 1651 in broth containing 16/8 $\mu \mathrm{g} / \mathrm{ml}$ AMC. (MP4 2375 kb)

Additional file 10: Video 9. Video imaging of B. pseudomallei ATCC 23343 in broth containing 8/4 $\mu \mathrm{g} / \mathrm{ml}$ AMC. (MP4 $1024 \mathrm{~kb}$ )

Additional file 11: Video 10. Video imaging of B. pseudomallei ATCC 23343 in broth containing 16/8 $\mu \mathrm{g} / \mathrm{ml}$ AMC. (MP4 662 kb)

Additional file 12: Video 11. Video imaging of B. pseudomallei ATCC 23343 in broth containing 32/16 $\mathrm{g} / \mathrm{ml} \mathrm{AMC.} \mathrm{(MP4} 495 \mathrm{~kb}$ ) 
Additional file 13: Video 12. Video imaging of B. mallei KC1092 in broth containing 8 rg/ml IPM. (MP4 $279 \mathrm{~kb}$ )

\section{Abbreviations}

AMC: Amoxicillin-clavulanic acid; AST: Antimicrobial susceptibility test; BMBL: Biosafety in Microbiological and Biomedical Laboratories; BMD: Broth microdilution; BSC: Biological safety cabinet; CAMHB: Cation-adjusted Mueller Hinton broth; CAZ: Ceftazidime; CIP: Ciprofloxacin; CLSI: Clinical and Laboratory Standards Institute; DOX: Doxycycline; GEN: Gentamicin; IPM: Imipenem; MALDI-TOF MS: Matrix assisted laser desorption ionization-time of flight, mass spectrometry; MDR: Multidrug-resistant; MIC: Minimal inhibitory concentration; NS: Non-susceptible; PAPR: Power air-purifying respirator; PBPS: Penicillin-binding proteins; PPE: Personal protective equipment; SBA: Trypticase Soy Agar II with 5\% sheep blood; SD: Standard deviation; SEAL: Segmentation and Extraction of Average Length; SESA: Segmentation and Extraction Surface Area; SXT: Trimethoprim-sulfamethoxazole; TES: N-tris(hydroxymethyl) methyl-2-aminoethanesulfonic acid

\section{Acknowledgements}

We thank Jeannine M. Petersen in the Division of Vector-Borne Diseases as well as Alex R. Hoffmaster, Jay E. Gee and Mindy G. Elrod in the Division of High-Consequence Pathogens and Pathology at the Centers for Disease Control and Prevention for their review of this manuscript. We also acknowledge the team at BioSense Solutions ApS (Farum, Denmark) for their technical support.

\section{Funding}

This work was supported by an interagency agreement HDTRA1213740 with the Department of Defense (DoD), Defense Threat Reduction Agency (DTRA) and Joint Science and Technology Office (JSTO). The funding bodies did not play a role in the design of the study, in the collection, analysis and interpretation of data, or in writing the manuscript.

\section{Availability of data and materials}

Datasets used and analyzed for this study are available from the corresponding author upon request.

\section{Disclaimer}

The findings and conclusions in this report are those of the authors and do not necessarily represent the official position of the Centers for Disease Control and Prevention. Use of trade names is for identification only and does not imply endorsement by the Centers for Disease Control and Prevention.

\section{Authors' contributions}

Design and conception of experiments: HM, DS. Execution of experiments: HM. Data analysis: HM. Drafting the manuscript: HM, DS. Corrections and approval of the final manuscript: HM, DS. Both authors read and approved the final manuscript

\section{Ethics approval and consent to participate} Not Applicable.

\section{Consent for publication}

Not Applicable.

\section{Competing interests}

The authors' declare that they have no competing interests.

\section{Publisher's Note}

Springer Nature remains neutral with regard to jurisdictional claims in published maps and institutional affiliations.

\section{Received: 12 April 2018 Accepted: 16 November 2018}

\section{Published online: 18 December 2018}

\section{References}

1. Centers for Disease C, Prevention DoH, Human S. Possession, use, and transfer of select agents and toxins; biennial review. Final rule. Fed Regist. 2012;77:61083-115.

2. Wagar E. Bioterrorism and the role of the clinical microbiology laboratory. Clin Microbiol Rev. 2016;29:175-89.
3. Ryan JR, Glarum JF. Biosecurity and Bioterrorism: Containing and Preventing Biological Threats. 1st ed. Burlington: Butterworth-Heinemann; 2008.

4. Woods LCJB. USAMRIID's medical Management of Biological Casualites Handbook. 6th ed. Fort Detrick. Frederick: U.S. Army Medical Research Institute of Infectious Disease; 2005

5. Ligon BL. Plague: a review of its history and potential as a biological weapon. Semin Pediatr Infect Dis. 2006;17:161-70.

6. Gottfried RS. The black death. Natural and human disaster in medieval europe. New York, N Y: The Free Press; 1983.

7. Perry RD, Fetherston JD. Yersinia pestis--etiologic agent of plague. Clin Microbiol Rev. 1997:10:35-66.

8. World Health Organization ROfA: Plague Outbreatk Madagascar, External Situation Report 13. 2017 http://wwwafrowhoint/health-topics/plague/ plague-outbreak-situation-reports.

9. Mead PS. Plague in Madagascar - a tragic opportunity for improving public health. N Engl J Med. 2018;378:106-8

10. Vandamm JP, Rajanna C, Sharp NJ, Molineux IJ, Schofield DA. Rapid detection and simultaneous antibiotic susceptibility analysis of Yersinia pestis directly from clinical specimens by use of reporter phage. J Clin Microbiol. 2014:52:2998-3003.

11. Butler T. Plaque into the 21st century. Clin Infect Dis. 2009:49:736-42.

12. Ryzhko I, Shcherbaniuk A, Samokhodkina E, Tsuraeva R, Mishn'kin B, Kasatkina I, Zhigalova T. Virulence of rifampicin and quinolone resistant mutants of strains of plague microbe with Frat and Fra-phenotypes. Antibiot Khimioter. 1994;39:32-6.

13. Inglesby TV, Dennis DT, Henderson DA, Bartlett JG, Ascher MS, Eitzen E, Fine AD, Friedlander AM, Hauer J, Koerner JF. Plague as a biological weapon: medical and public health management. Jama. 2000;283:2281-90.

14. Alibek K, Handelman S. Biohazard. New York, NY: Random House; 1999.

15. Galimand M, Carniel E, Courvalin P. Resistance of Yersinia pestis to antimicrobial agents. Antimicrob Agents Chemother. 2006;50:3233-6.

16. Galimand M, Guiyoule A, Gerbaud G, Rasoamanana B, Chanteau S, Carniel E, Courvalin P. Multidrug resistance in Yersinia pestis mediated by a transferable plasmid. N Engl J Med. 1997;337:677-80.

17. Guiyoule A, Gerbaud G, Buchrieser C, Galimand M, Rahalison L, Chanteau S, Courvalin P, Carniel E. Transferable plasmid-mediated resistance to streptomycin in a clinical isolate of Yersinia pestis. Emerg Infect Dis. 2001;7:43-8.

18. Elschner MC. Burkholderia mallei infection in a horse imported from Brazil. Equine Vet Educ. 2009;21:147-50.

19. Malik P, Khurana SK, Dwivedi SK. Re-emergence of glanders in India - report of Maharashtra state. Indian J Microbiol. 2010;50:345-8.

20. Naureen A. Antimicrobial susceptibility of 41 Burkholderia mallei isolates from spontaneous outbreaks of equine glanders in Punjab, Pakistan. $J$ Equine Vet. 2010;30:134-41.

21. Gilad J, Harary I, Dushnitsky T, Schwartz D, Amsalem Y. Burkholderia mallei and Burkholderia pseudomallei as bioterrorism agents: national aspects of emergency preparedness. Isr Med Assoc J. 2007:9:499-503.

22. Rubin $\mathrm{HL}$, Alexander $\mathrm{AD}$, Yager RH. Melioidosis--a military medical problem? Mil Med. 1963:128:538-42.

23. Perumal Samy R, Stiles BG, Sethi G, Lim LHK. Melioidosis: clinical impact and public health threat in the tropics. PLoS Negl Trop Dis. 2017:11:e0004738.

24. Bugrysheva JV, Sue D, Gee JE, Elrod MG, Hoffmaster AR, Randall LB, Chirakul S, Tuanyok A, Schweizer HP, Weigel LM. Antibiotic resistance markers in Burkholderia pseudomallei strain Bp1651 identified by genome sequence analysis. Antimicrob Agents Chemother. 2017;61:e00010-17.

25. Schweizer HP. Mechanisms of antibiotic resistance in Burkholderia pseudomallei: implications for treatment of melioidosis. Future Microbiol. 2012;7:1389-99.

26. Wiersinga WJ, Currie BJ, Peacock SJ. Melioidosis. N Engl J Med. 2012;367: 1035-44.

27. Wuthiekanun V, Amornchai P, Saiprom N, Chantratita N, Chierakul W, Koh GC, Chaowagul W, Day NP, Limmathurotsakul D, Peacock SJ. Survey of antimicrobial resistance in clinical Burkholderia pseudomallei isolates over two decades in Northeast Thailand. Antimicrob Agents Chemother. 2011;55: 5388-91.

28. Wuthiekanun V, Cheng AC, Chierakul W, Amornchai P, Limmathurotsakul D, Chaowagul W, Simpson AJ, Short JM, Wongsuvan G, Maharjan B, et al. Trimethoprim/sulfamethoxazole resistance in clinical isolates of Burkholderia pseudomallei. J Antimicrob Chemother. 2005;55:1029-31.

29. Chantratita N, Rholl DA, Sim B, Wuthiekanun V, Limmathurotsakul D, Amornchai P, Thanwisai A, Chua HH, Ooi WF, Holden MT, et al. Antimicrobial 
resistance to ceftazidime involving loss of penicillin-binding protein 3 in Burkholderia pseudomallei. Proc Natl Acad Sci U S A. 2011;108:17165-70.

30. Dance DA, Wuthiekanun V, Chaowagul W, Suputtamongkol Y, White NJ. Development of resistance to ceftazidime and co-amoxiclav in Pseudomonas pseudomallei. J Antimicrob Chemother. 1991;28:321-4.

31. Limmathurotsakul D, Peacock SJ. Melioidosis: a clinical overview. Br Med Bull. 2011;99:125-39.

32. Lipsitz R, Garges S, Aurigemma R, Baccam P, Blaney DD, Cheng AC, Currie BJ, Dance D, Gee JE, Larsen J, et al. Workshop on treatment of and postexposure prophylaxis for Burkholderia pseudomallei and B. mallei infection, 2010. Emerg Infect Dis. 2012;18:e2.

33. Kenny DJ, Russell P, Rogers D, Eley SM, Titball RW. In vitro susceptibilities of Burkholderia mallei in comparison to those of other pathogenic Burkholderia spp. Antimicrob Agents Chemother. 1999;43:2773-5.

34. Heine HS, England MJ, Waag DM, Byrne WR. In vitro antibiotic susceptibilities of Burkholderia mallei (causative agent of glanders) determined by broth microdilution and E-test. Antimicrob Agents Chemother. 2001;45:2119-21.

35. Van Zandt KE, Greer MT, Gelhaus HC. Glanders: an overview of infection in humans. Orphanet J Rare Dis. 2013;8:131.

36. Ansari M, Minou M. Two cases of chronic human glanders treated with sulfonamides. Ann Inst Pasteur. 1951;81:98-102.

37. Howe C, Miller WR. Human glanders; report of six cases. Ann Intern Med. 1947;26:93-115.

38. CLSI. Methods for Antimicrobial Dilution and Disk Susceptiblity Testing of Infrequently Isolated or Fastidious Bacteria M45. 3rd ed. Wayne, PA: Clinical and Laboratory Standards Institute; 2016.

39. Cox CR, Saichek NR, Schweizer HP, Voorhees KJ. Rapid Burkholderia pseudomallei identification and antibiotic resistance determination by bacteriophage amplification and MALDI-TOF MS. Bacteriophage. 2014;4:e29011.

40. Schofield DA, Sharp NJ, Vandamm J, Molineux IJ, Spreng KA, Rajanna C, Westwater C, Stewart GC. Bacillus anthracis diagnostic detection and rapid antibiotic susceptibility determination using 'bioluminescent' reporter phage. J Microbiol Methods. 2013;95:156-61.

41. Steinberger-Levy I, Zahavy E, Cohen S, Flashner Y, Mamroud E, Aftalion M, Gur D, Ber R. Enrichment of Yersinia pestis from blood cultures enables rapid antimicrobial susceptibility determination by flow cytometry. Adv Exp Med Biol. 2007;603:339-50.

42. Gould IM, MacKenzie FM. The response of Enterobacteriaceae to betalactam antibiotics-'round forms, filaments and the root of all evil'. J Antimicrob Chemother. 1997;40:495-9.

43. Hanberger H, Nilsson LE, Nilsson M, Maller R. Post-antibiotic effect of betalactam antibiotics on gram-negative bacteria in relation to morphology, initial killing and MIC. Eur J Clin Microbiol Infect Dis. 1991;10:927-34.

44. McLaughlin HP, Gargis AS, Michel P, Sue D, Weigel LM. Optical screening for rapid antimicrobial susceptibility testing and for observation of phenotypic diversity among strains of the genetically clonal species Bacillus anthracis. J Clin Microbiol. 2017;55:959-70.

45. Propst KL, Mima T, Choi KH, Dow SW, Schweizer HP. A Burkholderia pseudomallei deltapurM mutant is avirulent in immunocompetent and immunodeficient animals: candidate strain for exclusion from select-agent lists. Infect Immun. 2010;78:3136-43.

46. U.S Department of Health and Human Services (U.S. HHS) CfDCaPC, National Institutes of Health (NIH). Biosafety in microbiological and biomedical laboratories. 5th ed. Washington, DC: Government Printing Office; 2009.

47. Fredborg M, Andersen KR, Jorgensen E, Droce A, Olesen $T$, Jensen BB, Rosenvinge FS, Sondergaard TE. Real-time optical antimicrobial susceptibility testing. J Clin Microbiol. 2013;51:2047-53.

48. Canali C, Spillum E, Valvik M, Agersnap N, Olesen T. Real-time digital bright field Technology for Rapid Antibiotic Susceptibility Testing. Methods Mo Biol. 2018;1736:75-84.

49. Bugrysheva JV, Lascols C, Sue D, Weigel LM. Rapid antimicrobial susceptibility testing of Bacillus anthracis, Yersinia pestis, and Burkholderia pseudomallei using laser light scattering technology. J Clin Microbiol. 2016;54(6):1462-71.

50. Schofield DA, Molineux IJ, Westwater C. Rapid identification and antibiotic susceptibility testing of Yersinia pestis using bioluminescent reporter phage. J Microbiol Methods. 2012;90:80-2.

51. Saint-Ruf C, Crussard S, Franceschi C, Orenga S, Ouattara J, Ramjeet M, Surre J, Matic I. Antibiotic susceptibility testing of the gram-negative Bacteria based on flow cytometry. Front Microbiol. 2016;7:1121.
52. Manzeniuk IN, Dorokhin W, Svetoch EA. The efficacy of antibacterial preparations against Pseudomonas mallei in in-vitro and in-vivo experiments. Antibiot Khimioter. 1994;39:26-30.

53. Thibault FM, Hernandez E, Vidal DR, Girardet M, Cavallo JD. Antibiotic susceptibility of 65 isolates of Burkholderia pseudomallei and Burkholderia mallei to 35 antimicrobial agents. J Antimicrob Chemother. 2004;54:1134-8.

54. Sauvage E, Kerff F, Terrak M, Ayala JA, Charlier P. The penicillin-binding proteins: structure and role in peptidoglycan biosynthesis. FEMS Microbiol Rev. 2008;32:234-58.

55. Spratt BG. Distinct penicillin binding proteins involved in the division, elongation, and shape of Escherichia coli K12. Proc Natl Acad Sci U S A. 1975;72:2999-3003.

56. Waxman DJ, Strominger JL. Penicillin-binding proteins and the mechanism of action of beta-lactam antibiotics. Annu Rev Biochem. 1983;52:825-69.

57. Kitano K, Tomasz A. Triggering of autolytic cell wall degradation in Escherichia coli by beta-lactam antibiotics. Antimicrob Agents Chemother. 1979;16:838-48.

58. Tomasz A. From penicillin-binding proteins to the lysis and death of bacteria: a 1979 view. Rev Infect Dis. 1979;1:434-67.

59. Ferreira RC, Park JT, Camelo D, De Almeida DF, Ferreira LC. Interactions of Yersinia pestis penicillin-binding proteins with beta-lactam antibiotics. Antimicrob Agents Chemother. 1995;39:1853-5.

60. Hayes MV, Orr DC. Mode of action of ceftazidime: affinity for the penicillinbinding proteins of Escherichia coli K12, Pseudomonas aeruginosa and Staphylococcus aureus. J Antimicrob Chemother. 1983;12:119-26.

61. Fredborg M, Rosenvinge FS, Spillum E, Kroghsbo S, Wang M, Sondergaard TE. Automated image analysis for quantification of filamentous bacteria. BMC Microbiol. 2015;15:255.

62. Chen K, Sun GW, Chua KL, Gan YH. Modified virulence of antibiotic-induced Burkholderia pseudomallei filaments. Antimicrob Agents Chemother. 2005; 49:1002-9.

63. Kjeldsen TS, Sommer MO, Olsen JE. Extended spectrum beta-lactamaseproducing Escherichia coli forms filaments as an initial response to cefotaxime treatment. BMC Microbiol. 2015;15:63.

64. Greenwood D, O'Grady F, Baker P. An in vitro evaluation of clavulanic acid, a potent, broad-spectrum beta-lactamase inhibitor. J Antimicrob Chemother. 1979;5:539-47.

65. Kocaoglu $\mathrm{O}$, Carlson EE. Profiling of beta-lactam selectivity for penicillinbinding proteins in Escherichia coli strain DC2. Antimicrob Agents Chemother. 2015:59:2785-90.

66. Severin A, Severina E, Tomasz A. Abnormal physiological properties and altered cell wall composition in Streptococcus pneumoniae grown in the presence of clavulanic acid. Antimicrob Agents Chemother. 1997;41:504-10.

67. Finlay J, Miller L, Poupard JA. A review of the antimicrobial activity of clavulanate. J Antimicrob Chemother. 2003;52:18-23.

68. Cuffini AM, Tullio V, lanni Palarchio A, Bonino A, Paizis G, Carlone NA. Enhanced effects of amoxycillin/clavulanic acid compared with amoxycillin and clavulanic acid alone on the susceptibility to immunodefenses of a penicillin-resistant strain of Streptococcus pneumoniae. Drugs Exp Clin Res. 1998;24:173-84

69. Davies TA, Page MG, Shang W, Andrew T, Kania M, Bush K. Binding of ceftobiprole and comparators to the penicillin-binding proteins of Escherichia coli, Pseudomonas aeruginosa, Staphylococcus aureus, and Streptococcus pneumoniae. Antimicrob Agents Chemother. 2007;51:2621-4.

70. Yang $Y$, Bhachech N, Bush K. Biochemical comparison of imipenem, meropenem and biapenem: permeability, binding to penicillin-binding proteins, and stability to hydrolysis by beta-lactamases. J Antimicrob Chemother. 1995;35:75-84

71. Smith MD, Wuthiekanun V, Walsh AL, White NJ. Susceptibility of Pseudomonas pseudomallei to some newer beta-lactam antibiotics and antibiotic combinations using time-kill studies. J Antimicrob Chemother. 1994:33:145-9.

72. Karger A, Stock R, Ziller M, Elschner MC, Bettin B, Melzer F, Maier T, Kostrzewa M, Scholz HC, Neubauer H, Tomaso H. Rapid identification of Burkholderia mallei and Burkholderia pseudomallei by intact cell matrixassisted laser desorption/ionisation mass spectrometric typing. BMC Microbiol. 2012;12:229

73. U'Ren JM, Schupp JM, Pearson T, Hornstra H, Friedman CL, Smith KL, Daugherty RR, Rhoton SD, Leadem B, Georgia S, et al. Tandem repeat regions within the Burkholderia pseudomallei genome and their application for high resolution genotyping. BMC Microbiol. 2007;7:23. 
74. Gee JE, Sacchi CT, Glass MB, De BK, Weyant RS, Levett PN, Whitney AM, Hoffmaster AR, Popovic T. Use of $16 \mathrm{~S}$ rRNA gene sequencing for rapid identification and differentiation of Burkholderia pseudomallei and B. mallei. J Clin Microbiol. 2003:41:4647-54.

75. Glass MB, Popovic T. Preliminary evaluation of the API 20NE and RapID NF plus systems for rapid identification of Burkholderia pseudomallei and B. mallei. J Clin Microbiol. 2005;43:479-83.

76. Bugrysheva JV, Sue D, Hakovirta J, Loparev VN, Knipe K, Sammons SA, Ranganathan-Ganakammal S, Changayil S, Srinivasamoorthy G, Weil MR, et al. Finished annotated genome sequence of Burkholderia pseudomallei strain Bp1651, a multidrug-resistant clinical isolate. Genome Announc. 2015; 3:e01427-15.

77. DeShazer D. Genomic diversity of Burkholderia pseudomallei clinical isolates: subtractive hybridization reveals a Burkholderia mallei-specific prophage in B. pseudomallei 1026b. J Bacteriol. 2004;186:3938-50.

78. Houghton RL, Reed DE, Hubbard MA, Dillon MJ, Chen H, Currie BJ, Mayo M, Sarovich DS, Theobald V, Limmathurotsakul D, et al. Development of a prototype lateral flow immunoassay (LFI) for the rapid diagnosis of melioidosis. PLoS Negl Trop Dis. 2014;8:e2727.

79. Jawetz EMK. Avirulent strains of Pasteurella pestis. J Infect Dis. 1943;73:124-43.

80. Achtman M, Morelli G, Zhu P, Wirth T, Diehl I, Kusecek B, Vogler AJ, Wagner DM, Allender CJ, Easterday WR, et al. Microevolution and history of the plague bacillus, Yersinia pestis. Proc Natl Acad Sci U S A. 2004;101:17837-42.

81. Chain PS, Hu P, Malfatti SA, Radnedge L, Larimer F, Vergez LM, Worsham P, Chu MC, Andersen GL. Complete genome sequence of Yersinia pestis strains Antiqua and Nepal516: evidence of gene reduction in an emerging pathogen. J Bacteriol. 2006;188:4453-63.

82. Eppinger M, Radnedge L, Andersen G, Vietri N, Severson G, Mou S, Ravel J, Worsham PL. Novel plasmids and resistance phenotypes in Yersinia pestis: unique plasmid inventory of strain Java 9 mediates high levels of arsenic resistance. PLoS One. 2012;7:e32911.

83. Eppinger M, Worsham PL, Nikolich MP, Riley DR, Sebastian Y, Mou S, Achtman M, Lindler LE, Ravel J. Genome sequence of the deep-rooted Yersinia pestis strain Angola reveals new insights into the evolution and pangenome of the plague bacterium. J Bacteriol. 2010;192:1685-99.

Ready to submit your research? Choose BMC and benefit from:

- fast, convenient online submission

- thorough peer review by experienced researchers in your field

- rapid publication on acceptance

- support for research data, including large and complex data types

- gold Open Access which fosters wider collaboration and increased citations

- maximum visibility for your research: over $100 \mathrm{M}$ website views per year

At $\mathrm{BMC}$, research is always in progress.

Learn more biomedcentral.com/submissions 